\title{
Reduced dwell-fatigue resistance in a Ni-base superalloy after
}

\section{short-term thermal exposure}

M. Hörnqvist, corresponding author

GKN Aerospace Engine Systems, Trollhättan, Sweden, and Department of Applied Physics, Chalmers University of Technology, Gothenburg, Sweden

L. Viskari

Department of Applied Physics, Chalmers University of Technology, Gothenburg, Sweden (presently AB SKF, Gothenburg, Sweden)

\begin{abstract}
The effect of short-term thermal exposure on microstructure and dwell-fatigue resistance of Ni-base superalloy 718Plus was investigated. Contrary to previous studies performed after long-term exposure, an increase in the dwell-fatigue crack growth rate was observed, which was connected to a small increase in the size of the hardening precipitates. The proposed controlling mechanism was the stress relaxation rate at the crack tip, and based on this a schematic model for the development of the properties during exposure is presented.
\end{abstract}

Keywords: Superalloy, dwell-fatigue, crack growth, thermal exposure

One of the major challenges for high-temperature structural materials is the environmentally induced grain boundary embrittlement $[1,2]$. The focus of the present paper is the coupling of microstructure and dwell-fatigue resistance in Allvac 718Plus (hereafter 718Plus). Previous results have shown that 718Plus is indeed sensitive to dwell-time fatigue [3-6], although less so than the main contender, Alloy 718. The effect of long-term thermal exposure on the 
dwell-fatigue crack growth is not as well studied, although it has been shown that 718Plus actually acquire improved dwell-fatigue resistance during exposure [4-6]. This was attributed to the loss of creep resistance with increasing size of the hardening precipitates, resulting in a more rapid relaxation of the crack tip stresses [4]. The exposure studies of 718Plus have all been carried out in an accelerated manner, where ageing temperatures of 1003-1033 K (730$760{ }^{\circ} \mathrm{C}$ ), well above the typical upper usage limit, and exposure times of 100 to $1000 \mathrm{~h}$ have been used [4-6]. While it was stated in ref. [6] that the accelerated ageing has been verified against experiments at $977 \mathrm{~K}\left(704{ }^{\circ} \mathrm{C}\right)$, the underlying data has so far not been disclosed (to the best of the authors knowledge) and the range of validity for the verification in terms of ageing times was not included. Contrary to this, it has been shown that there can actually be a reduction in the dwell-fatigue resistance in 718Plus during the early stages of exposure [3]. The present study aims to further investigate the effect of short-term thermal exposure on the dwell-fatigue crack growth in 718Plus, and relate the behavior to the evolution of the microstructure.

The investigated material, 718Plus (nominal composition in wt pct: $\mathrm{Ni}-18 \mathrm{Cr}-10 \mathrm{Fe}-9.0 \mathrm{Co}-$ $5.4 \mathrm{Nb}-2.8 \mathrm{Mo}-1.5 \mathrm{Al}-1.0 \mathrm{~W}-0.7 \mathrm{Ti}-0.02 \mathrm{C}-0.004 \mathrm{~B}-0.006 \mathrm{P})$, was obtained from forged rings with grain size ASTM 5. The material was subjected to pre-solution soaking followed by solution treatment and conventional two-step ageing (condition A). A number of specimens from each material were subjected to a second heat treatment cycle consisting of $140 \mathrm{~h}$ at 973 $\mathrm{K}\left(700{ }^{\circ} \mathrm{C}\right)$ and $460 \mathrm{~h}$ at $948 \mathrm{~K}\left(675^{\circ} \mathrm{C}\right)$ (condition E). This cycle was selected to mimic the thermal history of an aero engine structural component during service. The selection of times and temperatures were based on a larger test program regarding the effects of thermal exposure on the mechanical properties of 718 Plus of which the present study was a part. To compare with previous studies of 718Plus it should be noted that according to the Larson- 
Miller type argument in [6], the two steps correspond to roughly 5 and $4.5 \mathrm{~h}$, respectively, at $1033 \mathrm{~K}\left(760^{\circ} \mathrm{C}\right)$, or 22 and $19 \mathrm{~h}$ at $1003 \mathrm{~K}\left(730^{\circ} \mathrm{C}\right)$.

Fatigue crack growth tests were carried out on Kb-type specimens (4.3 x $10.2 \mathrm{~mm}$ crosssection) with semi-circular surface flaws generated from an electric discharge machined notch by room temperature fatigue cycling. The crack growth was monitored using direct current potential drop, and crack lengths were determined from the recorded potential drop using an experimental calibration function. Tests with purely cyclic and mixed (cyclic and dwellfatigue) loading were carried out at $873 \mathrm{~K}\left(600^{\circ} \mathrm{C}\right)$ and $973 \mathrm{~K}\left(700{ }^{\circ} \mathrm{C}\right)$. All cycles had an $R$ ratio of 0 . The cyclic blocks were conducted with a frequency of $0.5 \mathrm{~Hz}$, and the dwell cycles had a trapezoidal waveform with a $1 \mathrm{~s}$ loading ramp, $90 \mathrm{~s}$ dwell-time and $1 \mathrm{~s}$ unloading ramp. The tests were designed so that each dwell-fatigue block should give a total crack length increment of approximately $0.1-0.2 \mathrm{~mm}$. Hardness was measured using Vickers diamond pyramid indenter with a load of $10 \mathrm{~kg}$. Details regarding the material and mechanical testing can be found elsewhere [3].

Samples for microstructural studies were excised from the grips of the mechanical testing specimens. The samples were ground and polished to $1 \mu \mathrm{m}$ grit finish, lightly etched using Kallings no 2 reagent, and observed in an SEM using backscattered electrons. The area fraction of grain boundary precipitates was obtained from SEM images using the ImageJ software. For each material, between 2000 and 2500 precipitates were included in the analysis. The characterization of hardening precipitates was done using small-angle X-ray scattering (SAXS) to obtain averaged information over large volumes. The measurements where carried out at the I911-4 beam line (X-ray wavelength $\lambda=0.091 \mathrm{~nm}$ ) at the MAX II facility in Lund, Sweden. The self-consistent iterative method by Deschamps et al. [7] was 
used for determining the radius of gyration $R_{g}$ from the Guinier approximation at small $q$. The actual precipitate radius for mono-disperse spherical precipitates is given by the relation $r=\sqrt{5 / 3} R_{g}$, which has also been shown to hold well for uni-modal distributions with reasonable dispersion [7]. Phase determination was performed using a standard powder XRD equipment in Bragg-Brentano configuration, with a $\mathrm{Cu} \mathrm{X}$-ray source at $40 \mathrm{kV}$ acceleration voltage.

The results from the dwell-fatigue crack growth tests are shown in Fig. 1. For the block type tests only the data from the dwell-fatigue blocks is shown, but the behavior during the cyclic blocks was confirmed to coincide with the results from cyclic testing with the exception of a transient after the dwell-fatigue block. It is clear that the exposure has a detrimental effect on the dwell-fatigue resistance of 718Plus at both test temperatures, increasing the crack growth rate during dwell-conditions significantly while leaving the cyclic behavior unchanged. This is in stark contradiction to the previously reported behavior after long-term exposure, where significant improvements in the dwell-fatigue resistance were observed [4-6, 8]. Looking more closely on the behavior during the first and third dwell-fatigue blocks at $873 \mathrm{~K}\left(600{ }^{\circ} \mathrm{C}\right)$ (Fig. 2) a clear effect of exposure can be seen in the crack growth rate as a function of crack length. During the first block the crack growth rate in the A condition remains roughly constant, even decreasing somewhat, whereas the exposed material shows a continuously increasing crack growth rate after a short incubation time. The behavior is the same during the third block, but here also the A condition shows increasing crack growth rates after an initial stable/decreasing period. Clearly, both the damaging effect and the retardation due to the exposure are transient phenomena, which develop with time and cycling. 
The microstructure of the materials in the A condition is shown in Fig. 3, where the only observable features, beside the annealing twins and primary carbides, are the precipitates in the grain boundaries. Figure 4 clearly identifies the grain boundary precipitates as the $\mathrm{Ni}_{6} \mathrm{AlNb}$ version of the hexagonal $\mathrm{Ni}_{3} \mathrm{Ti} \eta$ phase [9], with no traces of peaks related to the $\delta$ phase. The $\gamma^{\prime}$ phase cannot be resolved in the XRD spectra due as the crystal structure and lattice parameters are too similar to the matrix gamma phase. No evidence of $\gamma$ '” can be seen in the 718Plus spectra, indicating that only small amounts of $\gamma^{\prime \prime}$, if any, can be expected. There were no distinguishable differences between the as-produced and exposed states. A summary of the structure quantification can be found in Table 1, together with corresponding values found in literature. It should be noted here that the area fraction of $\eta$ is most likely underestimated in the present case. The precipitates are present in two different morphologies (see Fig. 5), one more bulky plate-like and one much thinner and more elongated in shape [9]. The thinner precipitates were not always easily resolvable in the relatively low magnification SEM images used for image processing, so these precipitates will have been omitted in the analysis. A number of higher magnification images were processed as well, showing very similar size and area fractions before and after exposure. Although not verified statistically, this implies that there is no significant change in the thinner $\eta$ particles either.

The average $\gamma^{\prime}$ diameter obtained from the SAXS measurements (see Fig. 6) increased slightly from 32 to $36 \mathrm{~nm}$ during exposure. This is probably a very good approximation as 718Plus has a uni-modal distribution of spherical precipitates, e.g. [4]. Accordingly there was small increase in hardness from 437 to $450 \mathrm{HV} 10$. This is consistent with results from [10], where exposure at $923 \mathrm{~K}\left(650^{\circ} \mathrm{C}\right)$ or $973 \mathrm{~K}\left(700^{\circ} \mathrm{C}\right)$ produced slow hardening at least up to $10000 \mathrm{~h}$, whereas the hardness started to drop after about $30 \mathrm{~h}$ at $1033 \mathrm{~K}\left(760^{\circ} \mathrm{C}\right)$. 
From these results it is clear that the primary effect of the exposure on 718Plus is an increase in the size of the hardening precipitates, rather than any significant changes in the grain boundary precipitates. In the previous accelerated studies [4-6] not only the $\gamma$ ' size changed, but there was also simultaneous changes in the grain boundary precipitate content (Table 1).

It was suggested above that the nature of both damage and retardation mechanisms were time dependent in nature. For the present exposure conditions, the average creep rate of 718Plus (approximated as the rupture elongation divided by the rupture time measured during creep rupture tests) decreased after exposure, indicating an increased creep resistance [3]. Contrary to this, Cao et al. [6] showed that both primary and steady state creep rates increased with exposure time at $1033 \mathrm{~K}\left(760{ }^{\circ} \mathrm{C}\right)$, with primary creep being much more sensitive. Assuming that the same relationship holds for shorter exposure times, i.e. that both primary and steady state creep are affected in the same way but effect is larger on primary creep, the results from [3] would indicate an increase also in the primary creep rate. Here it should be noted that the shortest exposure time in [6] was $100 \mathrm{~h}$ at $1033 \mathrm{~K}\left(760^{\circ} \mathrm{C}\right)$, which is still very long compared to the present treatment based on the previous Larson-Miller argument.

According to [11], the creep rate in Alloy 718 has a minimum for $\gamma$ ' sizes of around $23 \mathrm{~nm}$. The maximum in the yield stress, which is an indication of a transition in the main deformation mechanism from shearing to looping, occurred at a $\gamma$ '” size somewhat larger than this $(27 \mathrm{~nm})$. Such behavior of the yield strength and creep resistance is schematically shown in Fig. 7. Assuming that this holds also for 718Plus, the properties of an initial microstructure (A in Fig. 7) with precipitates smaller than the size corresponding to the minimum in creep rate will develop accordingly during high-temperature exposure. For short-term exposures the creep resistance will increase, leading to slower relaxation of the crack tip stresses and 
increased dwell crack growth rates (e.g. B). After the minimum in creep rate the dwell-fatigue resistance will increase again, and subsequently the properties will be better than for the initial microstructure (e.g. C). The yield strength continues to increase until the maximum is reached. After sufficiently long exposures (e.g. D), the yield strength will reach values below that of the initial microstructure, while the dwell-fatigue resistance has increased further. Note that this is strictly valid only in the absence of changes in other phases, such as grain boundary precipitates or $\sigma$ phase, which can further influence the dwell-fatigue behavior. The present study corresponds to a transition $\mathrm{A} \rightarrow \mathrm{B}$, whereas most other investigations (e.g. Cao et al. [6]) contains exposures long enough to produce a microstructure corresponding to C or D.

Such a relationship as observed here is of course of outmost importance for practical applications where dwell-fatigue sensitive materials are employed. Based on previously published results one would expect the properties to improve during service, so that if the component was designed based on data for the as-received microstructure the safety margin would actually improve over time, as the microstructure becomes more resistant. The results presented here, on the other hand, show that there will be a period during service exposure where a significant reduction in dwell-fatigue properties can be expected. In many cases, the peak application temperature is reached only during a small part of the total service time. The majority of the time is spent at lower temperature where the coarsening is slow, and the period of reducing dwell-fatigue resistance can therefore be expected to be considerable in such applications. To be able to account for the changes in the crack growth behavior during the entire service life, it will be necessary to separate the effects of $\gamma^{\prime}$ coarsening and development of the grain boundary precipitates. If such relationships can be established, modeling of the microstructural evolution kinetics during operation can by used to predict the development of the dwell-fatigue properties. 
The mechanical data used in this study was produced in the EU FP7 project VITAL. The access to MAX II I911-4 beamline was provided through grant 20120098. Dr. Sylvio Haas, MAX-Lab, is kindly acknowledged for the assistance during the SAXS experiments. The Swedish Board for Strategic Research (SSF) is thanked for the financial support (grant SM110008), which allowed this study to be performed. 


\section{References}

[1] A. Pineau and S.D. Antolovich: Eng. Failure Analysis, 2009, vol. 16, pp. 2668-2697.

[2] D.A. Woodford: Energy Mater., 2006, vol. 1, pp. 59-79.

[3] M. Hörnqvist, L. Viskari, K. Stiller and G. Sjöberg: $7^{\text {th }}$ International Symposium on Superalloy 718 and Derivatives, TMS, Pittsburgh, PA, 2010, pp. 705-717.

[4] R.M. Kearsey, J. Tsang, S. Oppenheimer and E. McDevitt: JOM, 2012, vol. 64, pp. 241251.

[5] X. Liu, J. Xu, E. Barbero, W.D. Cao and R.L. Kennedy: Mater. Sci. Eng. A, 2008, vol. 474, pp. 30-38.

[6] W.D. Cao, in: $11^{\text {th }}$ International Symposium on Superalloys , TMS, Champion, PA, 2008, pp. 789-797.

[7] A. Deschamps and F. De Geuser: J. Applied Cryst., 2010, vol. 44, pp. 343-352.

[8] R.M. Kearsey, J. Tsang, S. Oppenheimer and E. McDevitt: $12^{\text {th }}$ International Symposium Superalloys, TMS, Champion, PA, 2012, pp. 741-749.

[9] E.J. Pickering, H. Mathur, A. Bhowmik, O.M.D.M. Messé, J.S. Barnard, M.C. Hardy, R. Krakow, K. Loehnert, H.J. Stone and C.M.F. Rae: Acta Mater., 2012, vol. 60, pp. 2757-2769. [10] P.J. Ennis, A. Strang, S.P. Gill, G.M. McColvin and H.V. Atkinson: Energy Mater., 2012, vol. 4, pp. 184-188.

[11] M.C. Chaturvedi and Y. Han: Mater. Sci. Eng., 1987, vol. 89, pp. L7-L10. 
Table 1. Exposure time, $t_{\text {exp }}$, exposure temperature, $T_{\text {exp }}$, corresponding Larson-Miller parameter, LMP, size and content of precipitates before and after exposure in this work and literature.

\begin{tabular}{|c|c|c|c|c|c|c|c|}
\hline Material & $\begin{array}{l}t_{\exp } \\
{[\mathrm{h}]}\end{array}$ & $\begin{array}{c}T_{\exp } \\
{\left[\mathrm{K}\left({ }^{\circ} \mathrm{C}\right)\right]}\end{array}$ & $\begin{array}{l}\text { LMP } \\
\text { [-] }\end{array}$ & $\begin{array}{c}\gamma^{\prime} \\
\text { diameter } \\
{[\mathrm{nm}]}\end{array}$ & $\begin{array}{c}\gamma^{\prime} \\
\text { content } \\
{[\%]}\end{array}$ & $\begin{array}{c}\eta / \delta \text { size } \\
{\left[\mu \mathrm{m}^{2}\right]}\end{array}$ & $\begin{array}{c}\eta / \delta \\
\text { content } \\
{[\%]}\end{array}$ \\
\hline 718Plus A & 0 & $\ldots$ & 0 & 32 & $\ldots$ & $0.47^{*}$ & $0.5^{\dagger}$ \\
\hline 718Plus E & $\begin{array}{l}140 \\
460\end{array}$ & $\begin{array}{l}973(700) \\
948(657)\end{array}$ & $\begin{array}{l}21.4 \\
21.3\end{array}$ & 36 & $\ldots$ & $0.44^{*}$ & $0.5^{\dagger}$ \\
\hline 718Plus [6] & 0 & $\cdots$ & 0 & 24 & $22.0^{7}$ & $\cdots$ & $0.5^{5}$ \\
\hline 718Plus [6] & 350 & $1033(760)$ & 23.1 & 53 & $18.7^{\dagger}$ & $\cdots$ & $2.9^{\ddagger}$ \\
\hline 718Plus [6] & 500 & $1033(760)$ & 23.3 & 65 & $20.7^{\ddagger}$ & $\cdots$ & $3.5^{*}$ \\
\hline $\begin{array}{l}\text { 718Plus [4, } \\
8]\end{array}$ & 0 & $\cdots$ & 0 & 27.6 & $\cdots$ & $\cdots$ & $6.5^{*}$ \\
\hline $\begin{array}{l}\text { 718Plus [4, } \\
8]\end{array}$ & 1000 & 1005 (732) & 23.0 & 59.6 & $\ldots$ & $\ldots$ & $5.9^{*}$ \\
\hline
\end{tabular}



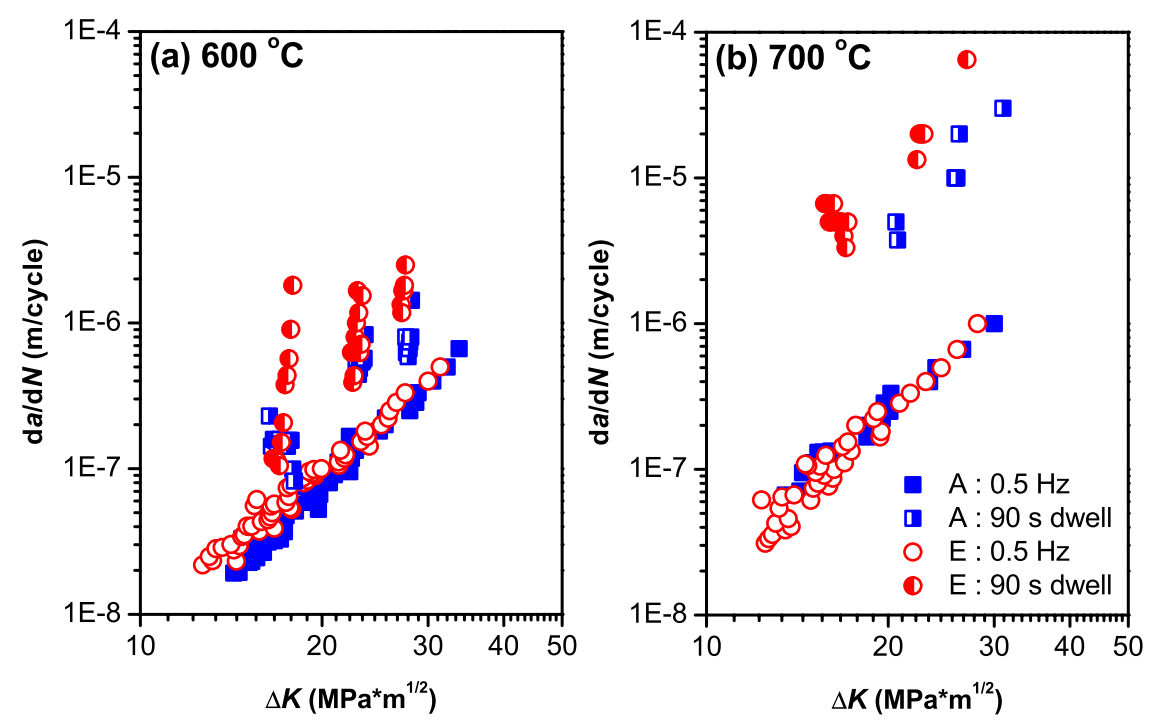

Figure 1. Cyclic and dwell-fatigue crack growth in 718Plus. (a) $873 \mathrm{~K}\left(600{ }^{\circ} \mathrm{C}\right)$; (b) $973 \mathrm{~K}$ $\left(700^{\circ} \mathrm{C}\right)$

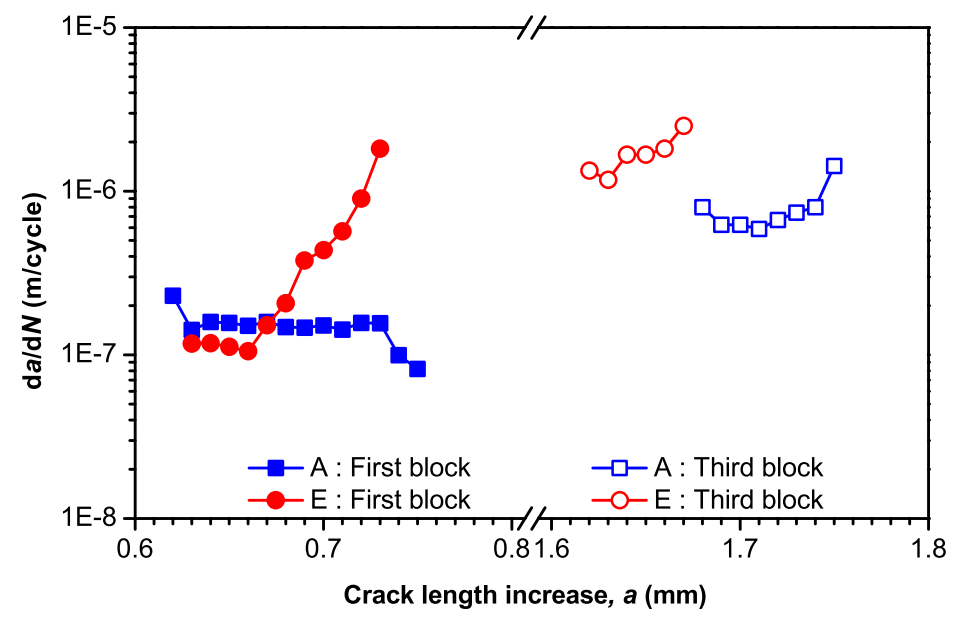

Figure 2. Crack growth rates during the first and third dwell-fatigue block at $873 \mathrm{~K}\left(600{ }^{\circ} \mathrm{C}\right)$.
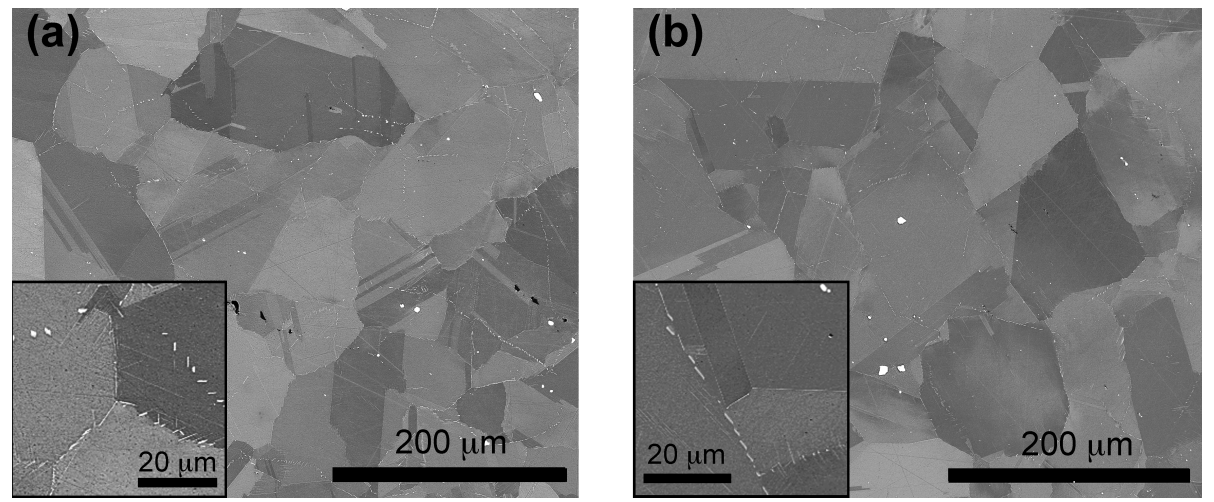

Figure 3. SEM image of 718Plus microstructure. (a) A condition; (b) E condition. 


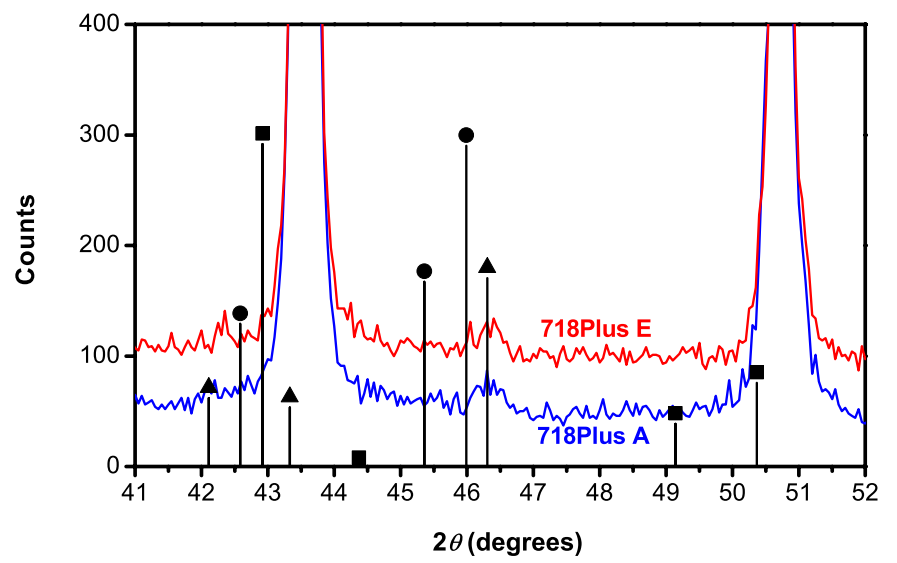

Figure 4. XRD spectra for $\mathrm{A}$ and $\mathrm{E}$ conditions: $\mathbf{-}-\gamma$ ” $\left(\mathrm{Ni}_{3} \mathrm{Nb}\right.$, tetragonal $\left.\mathrm{D}_{22}\right) ; \bullet-\delta$ $\left(\mathrm{Ni}_{3} \mathrm{Nb}\right.$, orthorhombic $\left.\mathrm{D}_{\mathrm{a}}\right) \boldsymbol{\Delta}-\eta\left(\mathrm{Ni}_{6} \mathrm{AlNb}\right.$, hexagonal $\left.\mathrm{D} 0_{24}\right)$.

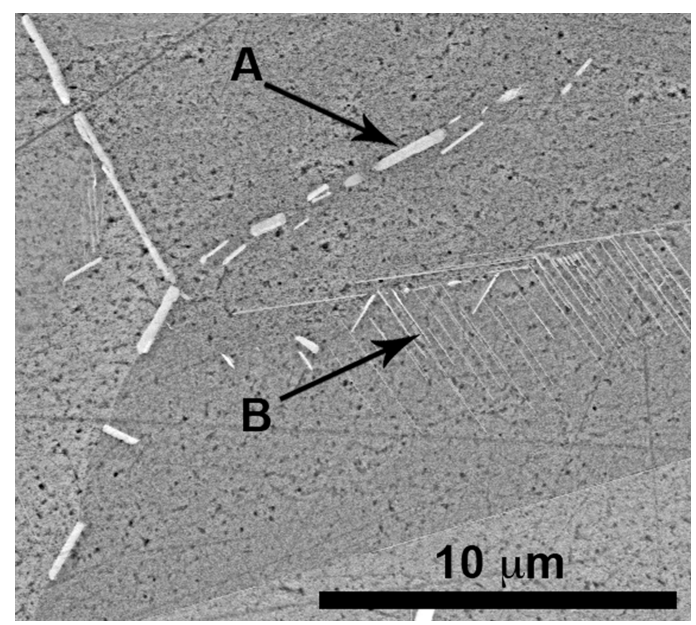

Figure 5. Observed morphologies of the $\eta$ phase. A - bulky plate-like shape and B - thin needle-like morphology.

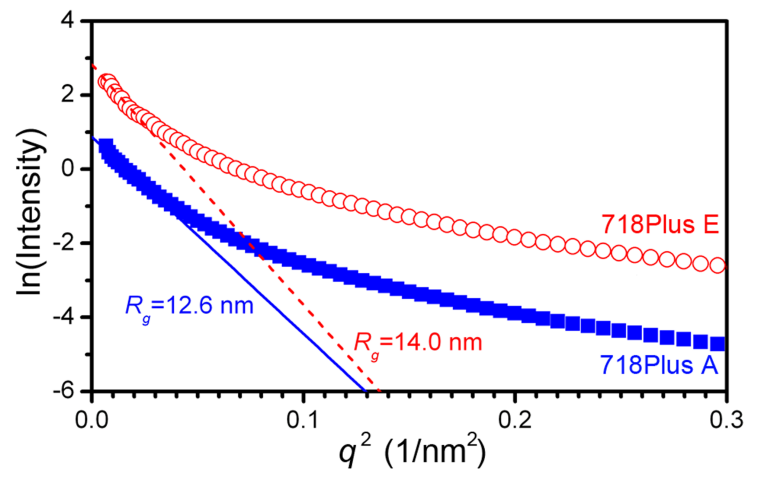

Figure 6. SAXS results (Guinier representation), including curve fit to determine the Guinier radius. 


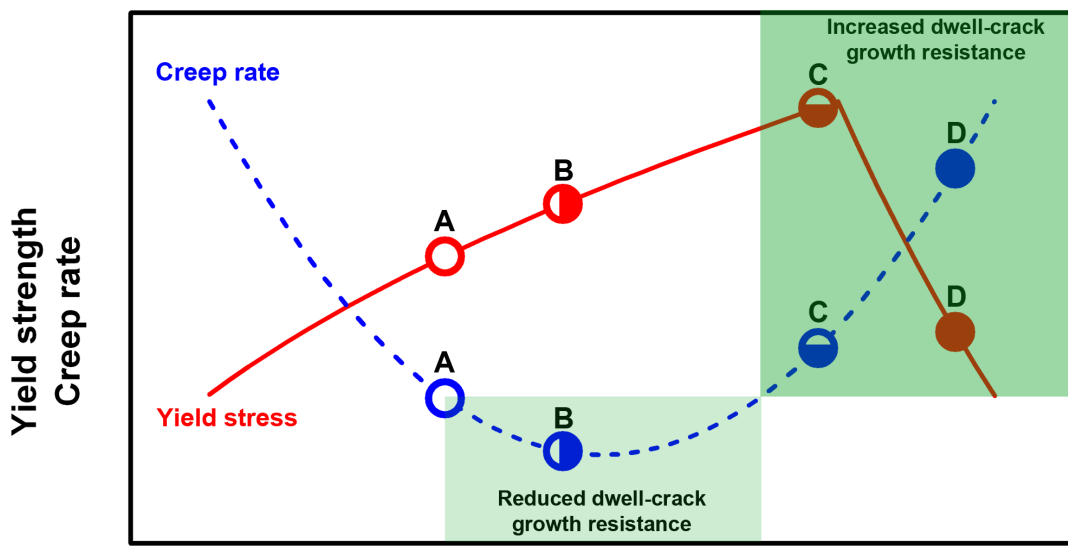

Precipitate size

Figure 7. Schematic of the development of precipitate size on creep rate and yield strength during exposure for a uni-modal size distribution: A - initial state; $\mathrm{B}$ - short-term exposure; C - intermediate exposure; D - long-term exposure. 